\title{
Enalapril Alters the Formation of the Collagen Matrix in Spontaneously Hypertensive Rats
}

\author{
Alfredo de Souza Bomfim, Carlos Alberto Mandarim-de-Lacerda \\ Rio de Janeiro, RJ - Brazil
}

\begin{abstract}
Objective - To assess the effect of the inhibition of the angiotensin-converting enzyme on the collagen matrix (CM) of the heart of newborn spontaneously hypertensive rats (SHR) during embryonic development.
\end{abstract}

Methods - The study comprised the 2 following groups of SHR ( $n=5$ each): treated group - rats conceived from SHR females treated with enalapril maleate $(15 \mathrm{mg}$. $\mathrm{kg}^{-1}$.day $\left.{ }^{-1}\right)$ during gestation; and nontreated group - offspring of nontreated females. The newborns were euthanized within the first 24 hours after birth and their hearts were removed and processed for histological study. Three fields per animal were considered for computer-assisted digital analysis and determination of the volume densities $\left(V_{v}\right)$ of the nuclei and $C M$. The images were segmented with the aid of Image Pro Plus ${ }^{\circledR}$ 4.5.029 software (Media Cybernetics).

Results - No difference was observed between the treated and nontreated groups in regard to body mass, cardiac mass, and the relation between cardiac and body mass. A significant reduction in the $V_{v}[$ matrix] and a concomitant increase in the $V_{v}$ [nuclei] were observed in the treated group as compared with those in the nontreated group.

Conclusion - The treatment with enalapril of hypertensive rats during pregnancy alters the collagen content and structure of the myocardium of newborns.

Key words: angiotensin, enalapril, collagen matrix, spontaneously hypertensive rats

Instituto de Biologia Roberto Alcântara Gomes - UERJ

Mailing address: Alfredo de Souza Bomfim - Rua Ministro Octávio Kelly, 221/904

- 24220-300 - Niterói, RJ, Brazil - Email: abomfim@unisys.com.br

English version by Stela Maris C. e Gandour
The quantitative and qualitative expression of the extracellular matrix $(\mathrm{ECM})$ is paramount for cardiac function ${ }^{1}$. In close relation with the cellular compartment, the components of the extracellular matrix are critical for transmitting information from the extracellular medium to cardiomyocytes $^{2}$. The interaction between the cellular compartment and the cardiac interstitium occurs in response to the physiological stimuli of normal development and in overload conditions, when the disproportional growth of the cellular and extracellular components is the basis for the ventricular dysfunction seen in pathological myocardial hypertrophy ${ }^{3-6}$. One of the key elements in understanding this heterogeneous pattern of growth and its deleterious effects on cardiac function is the quantitative and qualitative alteration in the collagen matrix. In fact, the interstitial fibrosis, by determining alterations in the myocardial physical structure, adversely affects ventricular function even when the hypertrophied cardiomyocytes still preserve the capacity of contraction ${ }^{5,7}$.

The type I and III collagens produced by fibroblasts are the major components of the myocardial collagen matrix ${ }^{8}$, whose development is regulated by several growth factors. Some studies have pointed out angiotensin II as a mediator of the growth of the collagen matrix that can induce the proliferation of fibroblasts and the increase in the collagen synthesis by fibroblasts ${ }^{9-11}$. Recently, AT1 and AT2 receptors for angiotensin II were identified in the fetal cardiac tissue drawing attention to the possibility that that hormone may regulate the expression of the myocardial collagen matrix from the earliest stages of cardiac embryonic formation ${ }^{12-14}$.

This study was designed to test the hypothesis that the inhibition of the angiotensin-converting enzyme (ACE) during the gestational period can interfere with myocardial morphogenesis by attenuating the content of the collagen matrix.

\section{Methods}

This study abided by the Guide for the Care and Use of Laboratory Animals published by the US National Institutes of Health (publication $n^{\circ} 85-23$, revised in 1985). We studied 
newborn rats generated from spontaneously hypertensive female rats (SHR) maintained in the vivarium of the laboratory of cardiovascular morphometry and morphology of the Instituto de Biologia Roberto Alcântara Gomes of the Universidade do Estado de Rio de Janeiro (IBRAG/UERJ). The pregnant females were maintained in polypropylene cages under controlled temperature $\left(21 \pm 1^{\circ} \mathrm{C}\right)$ and humidity $(60 \pm 10 \%)$ conditions, with day-night cycles of 12 hours (with artificial illumination), and air exhaust $(15 \mathrm{~min} / \mathrm{h})$. The newborn animals were divided into 2 groups ( $n=5$ in each) as follows: treated group - females treated with enalapril maleate $\left(15 \mathrm{mg} \cdot \mathrm{kg}^{-1}\right.$. day $\left.^{-1}\right)$ dissolved into drinking water, initiated during the mating period and maintained until the birth day; and the nontreated group. The newborns were analyzed (measurement of body and cardiac masses with a $0.001 \mathrm{~g}$-precision scale) and euthanized within the first 24 hours of life by decapitation.

The hearts were removed, immediately fixed by immersion in a Bouin solution for 48 hours at room temperature, and processed for inclusion in Paraplast plus ${ }^{\circledR}$ (Sigma Co., St Louis). Three mm-thick sections were stained with PicroSirius red to be studied with light microscopy. The slides were analyzed ( 3 fields per animal) on a Leica DMRBE ${ }^{\circledR}$ microscope coupled with a Kappa ${ }^{\circledR}$ camera under polarized light, and the images were digitalized for computer-assisted analysis. The images captured were semi-automatically segmented to determine the volume densities of nuclei $\left(\mathrm{V}_{\mathrm{v}}\right.$ nucleus) and collagen matrix ( $\mathrm{V}_{\mathrm{v}}$ matrix $)$ with the aid of Image Pro Plus 4.5.029 software (Media Cybernetics).

The biometric differences of the newborns were tested with the Student $t$ test (nonpaired). The stereological data were analyzed with the nonparametric Kolmogorov-Smirnov test. The statistical significance level of 0.05 was adopted ${ }^{15}$.

\section{Results}

The results are shown in table I and figures 1 to 3 . No difference was found between the treated and nontreated groups in regard to body mass, cardiac mass, and the relation between cardiac and body masses. A significant reduction in $\mathrm{V}_{\mathrm{v}}$ [matrix] and a concomitant increase in $\mathrm{V}_{\mathrm{v}}$ [nuclei] were observed in the treated group as compared with those in the nontreated group (figs. 1 and 2). The study of the collagen matrix with light microscopy stressed the differences between the groups of SHRs mainly with the use of polarized light, which showed a greater amount of collagen fibers in the newborns of the nontreated group (fig. 3).

\section{Discussion}

Angiotensin II plays an important role in the regulation of myocardial remodeling in response to overload conditions, such as in hypertensive disease of the heart and in the remaining portions of the heart suffering an acute myocardial infarction ${ }^{16}$. In hypertrophied hearts, although the cardiomyocytes preserve their capacity for contraction, the myocardium frequently exhibits striking functional

\begin{tabular}{|c|c|c|c|}
\hline \multirow[t]{2}{*}{ Dates } & \multicolumn{2}{|c|}{ Groups } & \multirow[t]{2}{*}{$\mathrm{p}$} \\
\hline & UT & $\mathrm{T}$ & \\
\hline $\mathrm{BM}(\mathrm{g})$ & $4.5 \pm 0.8$ & $4.8 \pm 1.0$ & NS \\
\hline $\mathrm{CM}(\mathrm{mg})$ & $37.0 \pm 2.6$ & $39.0 \pm 4.4$ & NS \\
\hline $\mathrm{BM} / \mathrm{CM}(\mathrm{mg} / \mathrm{g})$ & $8.5 \pm 1.4$ & $8.6 \pm 1.9$ & NS \\
\hline
\end{tabular}
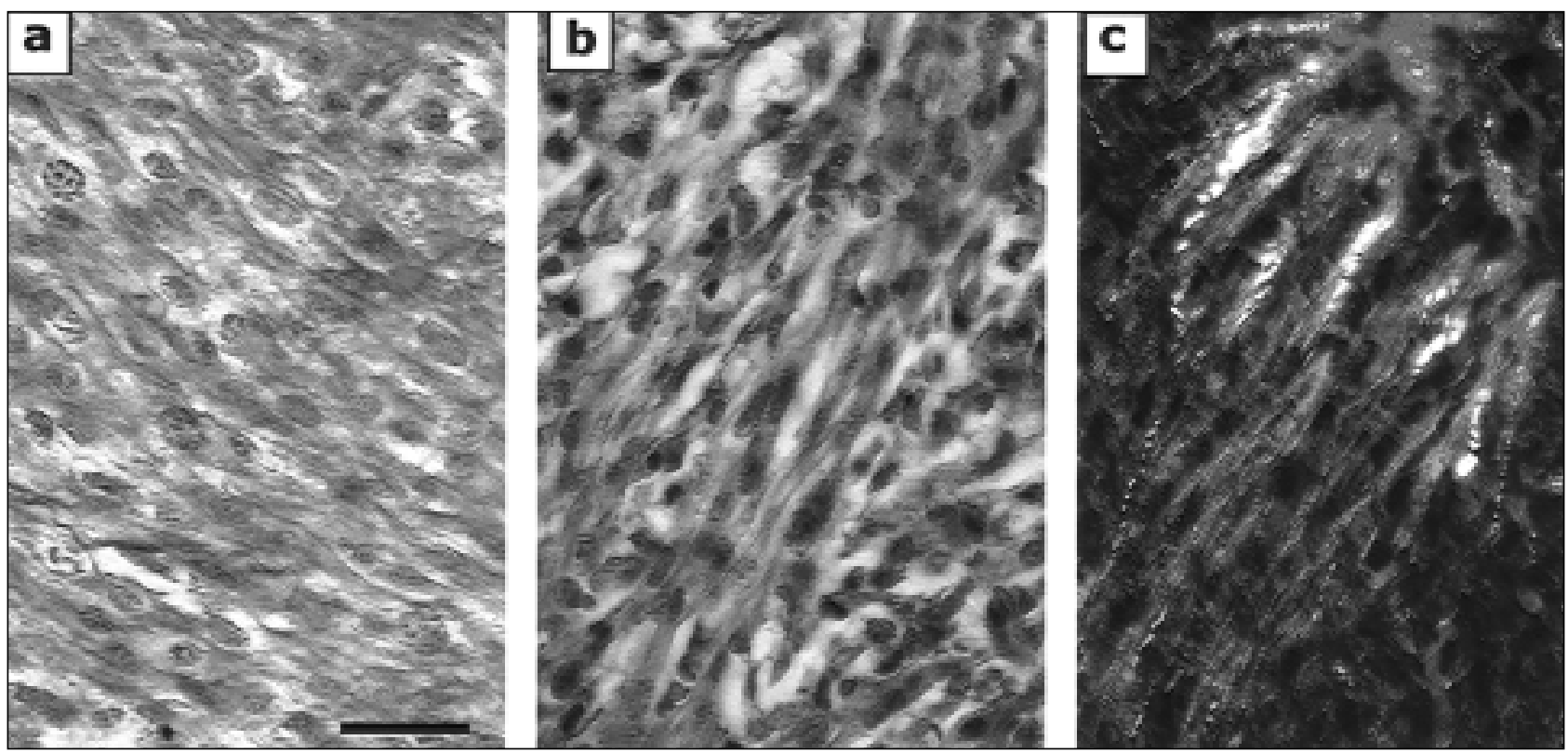

Fig. 1 - Photomicrographies of myocardium of newborn SHR satined with picrosirius red. A and B show the myocardium of offspring from dams untreated during gestation and C and $\mathrm{D}$ from dams treated with enalapril maleate during gestation. A and $\mathrm{C}$ were obtained on bright field, $\mathrm{B}$ and $\mathrm{D}$ were obtained under polarized light. Polarized light stress the myocardial collagen fibers in untreated animals (yellow-red shine) and the decrease in collagen matrix in newboard from treated dams $($ bar $=200 \mu \mathrm{m}$ ). 


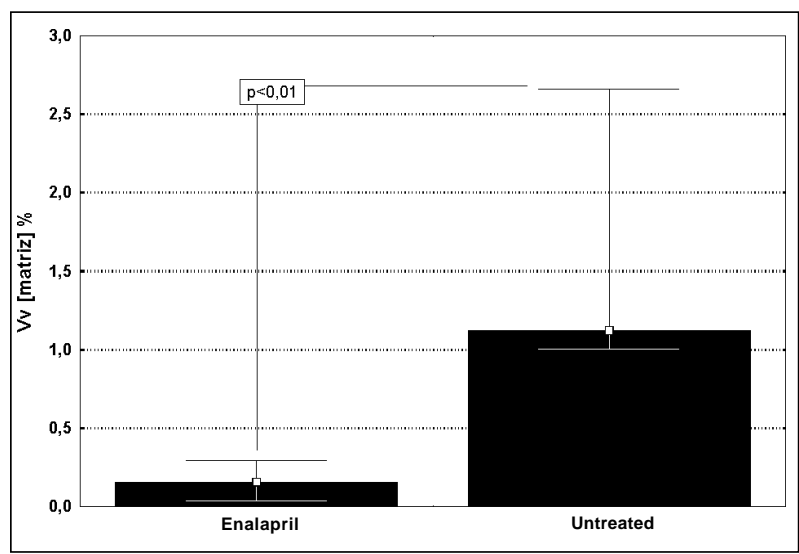

Fig. 2 - Variation of the volume density of collagen matrix in newboarn treated with enalapril maleate during gestation (left) and untreated (right). Box-whisker graph showing median and interquarter interval and upper and lower quarters. Difference was significant.

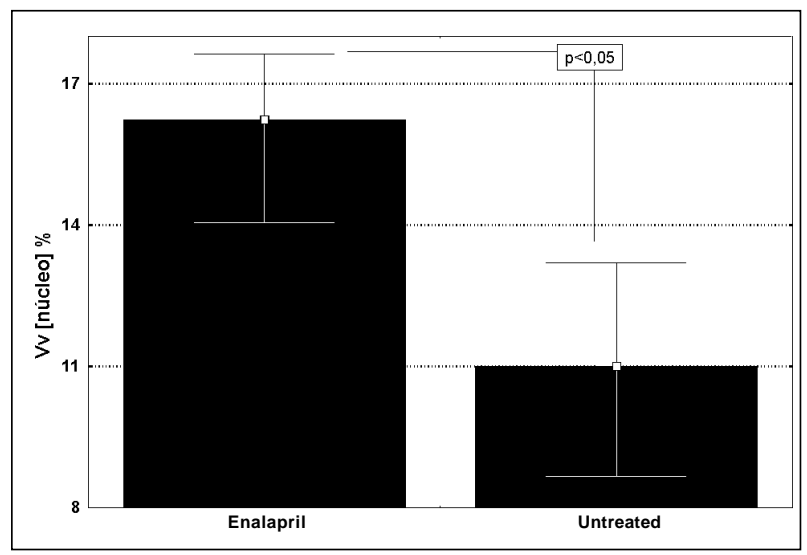

Fig. 3 - Variation of the volume density of nuclei in newboarn treated with enalapril maleateduring gestation (left) and untreated (right). Box-whisker graph showing median and interquarter interval and upper and lower quarters. Difference was significant.

alterations ${ }^{17}$. This apparent paradox is understood when analyzed considering the alterations observed in the structure of the myocardial interstitium. The concentration and organization of the components of the collagen matrix influence the physical characteristics of the cardiovascular tissue. The development of heart failure in arterial hypertension is related to the myocardial fibrosis in experimental animal models and in studies with human beings ${ }^{18}$.

The composition of the collagen matrix also affects the way the cells perceive the forces applied to the tissue. Myocardial stiffness influences the degree of deformation of the matrix in response to a mechanical stimulus; the cellular alignment determined by the matrix defines which cell portions will be exposed to the force. Through the cytoskeleton, all cells, not only the cardiomyocytes and smooth muscle cells, can generate tension ${ }^{19}$.

At least 5 types of collagen were found in the heart. The most abundant are types I and III, which together represent approximately $90 \%$ of cardiac collagen. The fibroblasts are the cells responsible for the synthesis and breakdown of collagen. Collagen has a high proportion of hydroxyproline, an amino acid present in low concentrations in a very limited number of other proteins. The content of tissue collagen may be assessed through the measurement of the content of hydroxyproline ${ }^{3}$. Because they have diverse physical characteristics, the relative proportion of collagen types I and III influences the properties of the myocardial tissue. Type I collagen forms thick fibers, which are highly resistant to tension, while type III collagen, more flexible, forms a thin net of fibrils. Together, both types are responsible for the structure and distensibility of the normal heart ${ }^{4}$. Three other types of collagen were observed in the heart. Types IV and $\mathrm{V}$ are constituents of the basement membrane. Type IV collagen was implicated in the regulation of angiogenesis as a constituent of the basement membrane of neoformed vessels ${ }^{20}$. Type VI is encountered in the interstitium together with other fibrillary collagens and plays a role in the regulation of the size of the fiber.

The renin-angiotensin-aldosterone system has been recognized as a key element in the events culminating with the development of myocardial fibrosis. Angiotensin II can stimulate the synthesis of collagen by fibroblasts through type AT1 receptors. Angiotensin II also inhibits the in vitro activity of collagenase ${ }^{5}$. Its action on fibroblasts seems to be modulated by calcium. The administration of angiotensin II increases the concentration of intracellular calcium in fibroblasts, an effect partially modulated by insulin ${ }^{21}$. The myocardial fibrosis induced by angiotensin II and aldosterone was shown to be attenuated by the concomitant administration of mibefradil, a calcium channel blocker ${ }^{22}$.

The positive impact of the pharmacological intervention on myocardial remodeling has been shown in clinical studies with the use of angiotensin-converting enzyme inhibitors in human beings experiencing acute myocardial infarction ${ }^{23,24}$ and in experimental essays with different models of hypertension. A recent clinical study assessing the effect of lisinopril in hypertensive patients with the echocardiographic diagnosis of left ventricular hypertrophy evidenced on biopsy reported that the drug could cause regression of preexisting fibrosis ${ }^{25}$. Similarly, the use of angiotensin-converting enzyme inhibitors in SHR resulted in attenuation and even regression of perivascular and interstitial fibrosis ${ }^{26}$.

The recognition of the action of angiotensin II in the genesis of the fibrosis that accompanies pathological myocardial hypertrophies indicates the possibility that this hormone may also be involved in the regulation of the physiological hypertrophy of myocardial growth and of the em bryonic development of the interstitial matrix. Recent studies have shown that AT1 and AT2 receptors for angiotensin II are expressed very early in fetal cardiac tissue. The high density of the receptors for angiotensin II in the embryonic myocardium has been interpreted as evidence that angiotensin II plays a regulator role in collagen expression during fetal development ${ }^{27}$. This function attributed to angiotensin II has been confirmed by experiments with rats treated with angiotensin-converting enzyme inhibitors during gestation, which resulted in abnormalities in the forma- 
tion of the skull, long bones, vertebrae, and ribs ${ }^{28-30}$. Our results are in accordance with this point of view. In the present study, the inhibition of the angiotensin-converting enzyme by the administration of enalapril maleate during the gestational period in SHR females resulted in the birth of animals with lower volume density of the myocardial collagen matrix as compared with that in the nontreated group. This finding suggests that the formation of the cardiac collagen matrix is modulated from the earliest stages of development by the action of angiotensin II and also the formation of the cellular compartment.

Thick collagen fibers were observed only in the nontreated group. In the group treated with enalapril, however, collagen synthesis was not entirely inhibited. These observations suggest that other regulators may be involved or that fibroblasts may be activated by locally produced angiotensin II. As the present study did not use the pharmacological blockade of AT1 and AT2 receptors, the hypothesis of the local action of angiotensin II could not be ruled out as suggested in previous studies ${ }^{31,32}$. Although previous studies using AT1 receptor blockade have very consistently shown their effect on the buildup of fetal collagen, a concomitant role played by bradykinin that accumulates due to the action of enalapril cannot be ruled out. Bradykinin can alter the renovation of collagen of fibroblasts in culture ${ }^{33}$. In addition, bradykinin is a mediator of the release of prostaglandins that may stimulate fibroblast expression and collagenase activity, which may increase collagen breakdown and attenuate collagen buildup ${ }^{34,35}$. The estimation of the functional impact of the phenotypic alteration induced by enalapril was not our objective. Alterations induced very early in embryogenesis may, theoretically, determine permanent alterations in cardiac structure, such as valvular malformations and septal defects, but this information can only be obtained through further observation of the growth of animals kept alive after birth.

\section{Acknowledgments}

We thank Thatiany de Souza Marinho and Ana Claudia Viana Soares by their technical support and CNPq and Faperj for the partial financial support.

\section{References}

1. Borg KT, Rubin K, Carver W, Samarel A, Terracio L. The cell biology of the cardiac interstitium. Trends Cardiovasc Med 1996;6:65-70.

2. Simpson DG, Carver W, Borg TK, Terracio L. The role of mechanical stimulation in the establishment and maintenance of muscle cell differentiation. Int Rev Cytol 1994;150:69-89.

3. Bishop JE, Laurent GJ. Collagen turnover and its regulation in the normal and hypertrophying heart. Eur Heart J 1995;16(Suppl. C): 38-44.

4. Weber KT, Brilla CG. Pathological hypertrophy and cardiac interstitium. Fibrosis and renin-angiotensin-aldosterone system. Circulation 1991;83:1849-65.

5. Weber KT, Sun Y, Guarda E. Structural remodeling in hypertensive heart disease and the role of hormones. Hypertension 1994;23(part 2): 869-77.

6. Rossi MA. Pathologic fibrosis and connective tissue matrix in left ventricular hypertrophy due to chronic arterial hypertension in humans. J Hypertens 1998; 16:1031-41.

7. Weber KT, Sun Y, Guarda E, et al. Myocardial fibrosis in hypertensive heart disease: an overview of potential regulatory mechanisms. Eur Heart J 1995; 16(SupplC) 24-8

8. Weber KT. Cardiac interstitium in health and disease: the fibrillar collagen network. J Am Coll Cardiol 1989; 13: 1637-52.

9. RamirezFJA, Sun Y, Weber KT. Myocardial fibrosis associated with aldosterone or angiotensin II administration: attenuation by calcium channel blockade. J Mol Cell Cardiol 1998; 30: 475-83.

10. Makino N, Sugano M, Otsuka S, Hata T. Molecular mechanism of angiotensin II type I and type II receptors in cardiac hypertrophy of spontaneous hypertensive rats. Hypertension 1997; 30: 796-802.

11. Sun Y, Weber KT. Cardiac remodeling by fibrous tissue: role of local factors and circulating hormones. Ann Med 1998; 30(Suppl 1): 3-8.

12. Sechi LA, Sechi G, DeCarli S, Griffin CA, Schambelan M, BartoliE. Angiotensin receptors in the rat myocardium during pre- and postnatal development. Cardiologia 1993;38:471-6.

13. Everett AD, Fischer A, Tufro-McReddie A, Harris M. Developmental regulation of angiotensin type 1 and 2 receptor gene expression and heart growth. J Moll Cell Cardiol 1997; 29: 141-8.

14. Hunt RA, Ciuffo GM, Saavedra JM, Tucker DC. Quantification and localization of angiotensin II receptors and angiotensin-converting enzyme in the developing rat heart. Cardiovasc Res 1995; 29: 834-40.

15. Zar JH. Biostatistical analysis. Englewood Cliffs: Prentice-Hall 1984: 718

16. Morgan HE, Baker KM. Cardiac Hypertrophy. Mechanical, neural and endocrine dependence. Circulation 1991;83:13-25.

17. Conrad CH, Brooks WW, Hayes JA, Sen S, Robinson KG, Bing OH. Myocardial fibrosis and stiffness with hypertrophy and heart failure in the spontaneously hypertensive rat. Circulation 1995;91:161-70.

18. Rossi MA. Pathologic fibrosis and connective tissue matrix in left ventricular hypertrophy due to chronic arterial hypertension in humans. J Hypertens 1998; 16:1031-41.

19. Comper WD. Structure and function of the extracellular matrix of connective tissues. Part II. Molecular Components. New York: Harwood Academic, 1995.

20. Bonanno E, Iularo M, Madri JA, Nicosia RF. Type IV collagen modulates angiogenesis and neovessel survival in the rat aorta model. In Vitro Cell Dev Biol Animal 2000;36:336-40.

21. Ceolotto G, Pessina AC, Iori E, et al. Modulatory effect of insulin on release of calcium from human fibroblasts by angiotensin II. J Hypertens 1998;16:487-93.

22. Ramirez FJA, Sun Y, Weber KT. Myocardial fibrosis associated with aldosterone or angiotensin II administration: attenuation by calcium channel blockade. J Mol Cell Cardiol 1998;30:475-83.

23. Pfeffer MA. Left ventricular remodeling after acute myocardial infarction. Ann Rev Med 1995;46:455-66.

24. Pfeffer M. ACE inhibition in acute myocardial infarction. N Engl J Med 1995; 332:118-20.

25. Brilla CG, Funck RC, RuppH.Lisinopril-mediated regression of myocardial fibrosis in patients with hypertensive heart disease. Circulation 2000; 102: 1388-93.

26. Brilla CG, Janicki JS, Weber KT. Impaired diastolic function and coronary reserve in genetic hypertension: role of interstitial fibrosis and medial thickening of intramyocardial coronary arteries. Cir Res 1991; 69: 107-15.

27. Lamparter S, Sun Y, Weber KT. Angiotensin II receptor blockade during gestation attenuates collagen formation in the developing rat heart. Cardiovasc Res 1999;43:165-72.

28. Barr Jr M, Cohen Jr MM. ACE inhibitor fetopathy and hypocalvaria: the kidneyskull connection. Teratology 1991; 44: 485-95.

29. Spence SG, Allen HL, Cukierski MA, Manson JM, Robertson RT, Eydelloth RS. Defining the susceptible period of developmental toxicity for the AT-1 selective angiotensin II receptor antagonist losartan in rats. Teratology 1995; 51: 367-82.

30. Buttar HS. An overview of the influence of ACE inhibitors on fetal-placental circulation in perinatal development. Moll Cell Biochem 1997; 176: 61-71.

31. Yamada H, Fabris B, Allen AM, Jackson B, Johnston CI, Mendhelson FAO. Localization of angiotensin-converting enzyme in rat heart. Cir Res 1991; 68: 141-9.

32. Schunkert H, Jackson B, Tang SS, et al. Distribution and functional significance of cardiac angiotensin converting enzyme in hypertrophied rat hearts. Circulation 1993; 87: 1328-39.

33. Goldstein RH, Polgar P. The effect and interaction of bradykinin and prostaglandins on protein and collagen production by lung fibroblasts. J Biol Chem 1982; 257:8630-3.

34. Farmer SG, Burch RM. Biochemical and molecular pharmacology kinin receptors. Annu Rev Pharmacol Toxicol 1992; 32: 511-36.

35. Hall JM. Bradykinin receptors: pharmacological properties and biological roles. Pharmacol Ther 1992; 56: 131-91. 